\title{
A generic population model for the African tick Rhipicephalus appendiculatus
}

\author{
S. E. RANDOLPH* and D. J. ROGERS \\ Department of Zoology, University of Oxford, South Parks Road, Oxford OX1 3PS
}

(Received 8 Fanuary 1997 ; revised 26 February 1997; accepted 26 February 1997)

SUMMARY

We present a simulation population model for the African tick Rhipicephalus appendiculatus, based on previous analyses of the mortality factors most closely correlated with observed population changes at 11 sites in equatorial and South Africa. The model incorporates temperature-dependent rates of egg production and development, climate-driven densityindependent mortality rates, particularly during the adult-larval stage, and density-dependent regulation of both nymphs and adults. Diapause is also included for tick populations in southern Africa. The model successfully describes both the seasonality and annual range of variation in numbers of each tick stage observed at each of 4 test sites in Uganda, Burundi and South Africa. Sensitivity analysis showed that the final version of the model is robust to 4-fold variation in most parameter values (that were per force based on informed guesses), but is more sensitive to the regression coefficients determining density-dependent interstadial mortality (that were derived from analysis of field data). The model is able to predict the seasonality of ticks from a site in Kenya where a full prior population analysis was not possible because only adults and nymphs had been counted. The model is potentially applicable to other species of ticks, both tropical and temperate, to predict tick abundance and seasonality as risk factors for tick-borne diseases.

Key words: Rhipicephalus appendiculatus, ticks, population models, seasonality, distribution, abundance.

\section{INTRODUCTION}

Tick seasonal dynamics exert a major influence on the dynamics of transmission of tick-borne pathogens. They determine not only seasonally variable vector/host ratios, but also the time-delay between acquisition and transmission of pathogens by successive tick life-stages, that has a significant impact on the transmission potential through its effect on vector survival probabilities. A population model for the tick is thus the foundation for tick-borne pathogen transmission models and for explanations of spatial variation in the risk of infection, allowing spatially and temporally variable values to replace the constant tick population terms used previously (Medley, Perry \& Young, 1993). As parasites in their own right, ticks cause considerable direct damage to their hosts in addition to their rôle as vectors. Predictions of the resultant economic losses, and planning effective control strategies to limit them, will benefit from tick population models (e.g. Kaiser et al. 1988).

For insects, complete population models arising from population analyses that determined the key factors most closely correlated with the observed population changes, date from Varley \& Gradwell's classic study of the winter moth (Operophtera

* Corresponding author. Tel: 01865 271241. Fax: 01865

310447. E-mail: sarah.randolph@zoology.ox.ac.uk brumata (L)) (Varley \& Gradwell, 1968). In comparison with this long pedigree, population models for ticks (reviewed by Kitron \& Mannelli, 1994) are in their infancy, and there is none born of such population analyses. Furthermore, due to the complexity of tick life-cycles, which necessitates the prediction of the numbers of 3 life-stages (larvae, nymphs and adults) arising simultaneously from overlapping generations, most tick population models are, per force, simulation rather than analytical models. These include matrix models that are computationally simple, but biologically incomplete, when applied to 1 stage only (Lord, 1992), but become very complex when extended to multiple matrices, a different one for each stage (Sandberg, Awerbuch \& Spielman, 1992; Awerbuch, Sandberg \& Spielman, 1992). None of these matrix models includes any density-dependence and so all fail to predict stable equilibria. Of the tick population models based on the construction of age-specific lifetables, those developed by Haile \& Mount for 3 tick species in America (Haile \& Mount, 1987; Mount \& Haile, 1989; Mount et al. 1991, 1993) are deductive, using estimates of development and mortality rates derived from a large variety of field and laboratory studies. A description of the only complete population model for the African tick Rhipicephalus appendiculatus Neumann that gives a reasonably good fit to field observations in Burundi and Zimbabwe, T3HOST, has never been published 
beyond a summary outline of the principles (Floyd, Maywald \& Sutherst, 1987) and a graphical display of its output (Kaiser et al. 1988).

The wide distribution of $R$. appendiculatus throughout eastern and southern Africa is reflected in the variety of patterns of its seasonal activity (reviewed by Norval, Perry \& Young, 1992). In southern Africa, there are marked annual cycles of abundance of each life-stage (larva, nymph and adult) punctuated by near total absences for several months of each year. Nearer to the equator, ticks usually feed throughout the year and numbers vary far less, but still show discernible seasonality, especially in the immature stages. A single generic population model for ticks must capture this geographical variation in seasonality. Such a robust model can only arise from a quantitative explanation of the demographic processes that generate the observed patterns, and it will itself test that explanation by the accuracy with which it can predict these recorded observations. Only then can the model be used to make reliable predictions about the unknown. In this paper, we describe an inductive model for the population dynamics of $R$. appendiculatus developed on the basis of analyses of field populations at 11 sites in different parts of Africa. We present the model's output for 2 sites in East Africa (in Uganda and Burundi) and 2 sites in South Africa to illustrate the model's ability to predict correctly the contrasting situations in equatorial and temperate regions and the subtly different patterns within each of these regions.

Detailed quantitative analyses of published tick data sets (Randolph, 1994, 1997) from 2 sites in Uganda (Kaiser, Sutherst \& Bourne, 1982, 1991), 4 sites in Burundi (Kaiser et al. 1988), 1 site in each of Tanzania (McCulloch et al. 1968) and Zimbabwe (Short \& Norval, 1981) and 3 sites in South Africa (Rechav, 1981, 1982), have revealed that the observed variety of seasonal dynamics is generated by a remarkably consistent set of underlying processes that change quantitatively, but not qualitatively, in different parts of the tick's range. The key features include (a) temperature-dependent development rates; (b) facultative diapause, manifested as a delay in the onset of host-questing behaviour by adult ticks, thought to be induced by day-length conditions at certain times of the year (Rechav, 1981; Berkvens, Pegram \& Brandt, 1995); (c) very strong density dependence in the interstadial mortalities from larvae to nymphs and from nymphs to adults, probably caused by the hosts' responses during tick feeding; (d) density-independent mortality, caused by the impact of a critical abiotic factor acting on the off-host development stages, that dominates during the first interstadial period from adults to larvae; (e) tick questing activity characterized by a certain level of daily mortality plus a certain probability of successfully contacting a host. The parameter values can be varied, including setting some (e.g. diapause induction) to zero, as appropriate for each geographical site. The greatest between-site variation concerns which abiotic factor is best correlated with off-host density-independent mortality, i.e. is critical for the tick's survival; for most parts of the tick's range, moisture availability appears to be critical, although mortality is highest where it is both too dry and too wet, while in the coolest southern areas, low minimum temperatures are limiting (Randolph, 1994, 1997).

\section{THE MODEL, RaPOP}

\section{Model description}

In outline, the tick model (Fig. 1) predicts the number of ticks present (i.e. 'feeding') on a constant population of hosts over time. Ticks enter the feeding population on the hosts after periods of (a) development (which may or may not include diapause) from the previous life-stage, and (b) questing, which results in finding and attaching to a host at a stadialdependent constant rate. Mortalities imposed between successive feeding stages are either density independent or density dependent according to the relationships established by Randolph $(1994,1997)$. Each run of the model begins by fixing the sitespecific climatic variables of importance, and the various determinants of the mortalities for each tick life-stage. The model is calculated on a daily basis, but the output presents the number of ticks feeding on hosts at the mid-point of each 30-day month.

The model is initially 'seeded' with 5 adult ticks ( 2.5 males and 2.5 females) on each day throughout the first year. Adult female ticks are assumed to produce a total of 3000 eggs each, over a temperature-dependent period of time. Inspection of the $R$. appendiculatus egg-laying curves reported by Branagan (1973a) suggested the following mathematical description for the number of eggs laid per day, $n_{\text {eggsperday }}$.

$n_{\text {eggsperday }}=k\left[\left(1-\exp ^{r 1 t}\right) \exp ^{-r 2 t}\right]$,

where $r 1$ and $r 2$ are constants determining the rate at which egg-laying begins to increase $(r 1)$ and subsequently decline $(r 2)$ over time from the start of egg-laying ( $t$ days) and $k$ is a scaling factor ensuring that the total number of eggs laid per female is always 3000 ( $k$ depends upon the precise values of $r 1$ and $r 2$ and is obtained by integrating the term within the square brackets of eqn (1)). The time to peak egglaying $\left(t_{p}\right)$ is found by equating the differential of eqn (1) to zero,

$t_{p}=\frac{-\log [r 2 /(r 1+r 2)]}{r 1}$ days.

Branagan (1973a) presented his data as the total number of eggs laid at 4-day intervals. We selected 


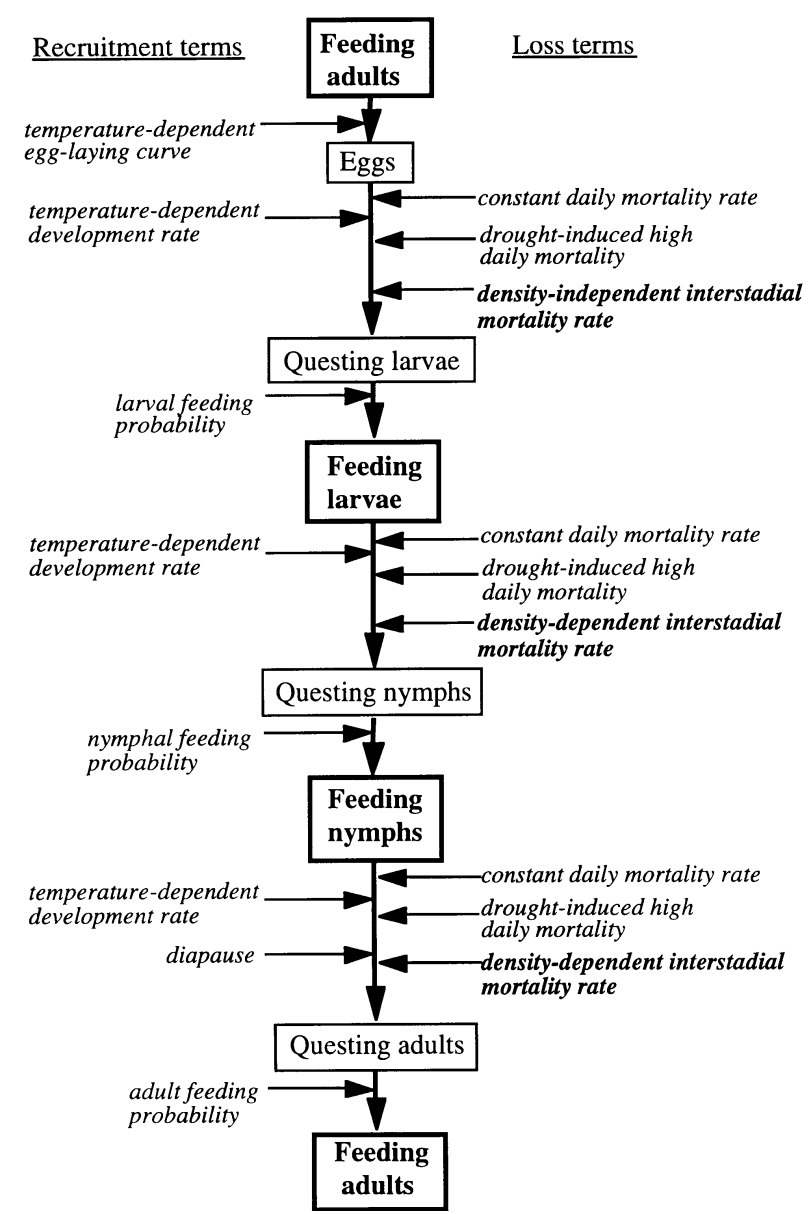

Fig. 1. The form of the population model, identifying the input parameters and the model output (predicted number of feeding ticks of each stage). Values for the slopes of the relationships in bold type were estimated directly from analyses of the field populations whose seasonality is predicted by the model.

values of $r 1$ and $r 2$ for eqn (1) to give 4-day egg production curves similar in both time of peak egg production and time over which the majority of eggs are laid for the 3 temperatures used by Branagan (18, 21 and $25^{\circ} \mathrm{C}$ ). Fig. 2 shows the daily egg production curves predicted by eqn (1) at 18,21 and $25^{\circ} \mathrm{C}$, with one example of the 4-day totals arising from them $\left(21^{\circ} \mathrm{C}\right)$.

The eggs present on any particular day (which are assumed to have been laid by females present on hosts 7 days previously) are assumed to develop at temperature-specific rates. Developmental periods are calculated by the day-degree summation method previously described by Randolph (1997). Briefly, the observed relationships between adult-to-larval developmental periods (including post-emergence inactivity) and ambient temperatures in the laboratory (Branagan, 1973a) and the field (Kaiser et al. 1988) are used to calculate a daily development rate at the current day's temperature and at the temperatures of days to come in the future, until the total development (obtained by summing the daily proportional development) reaches unity. The time taken for this limit to be reached is the total development time. In the model, daily mean temperatures are estimated by interpolation between the values of the mean monthly temperatures, which are assumed to apply to the mid-point (i.e. day 15) of their respective months.

Once development is completed, the active tick larvae are assumed to quest for hosts with a stadialspecific success rate (the 'feeding probability'). Whether or not the larvae survive to the feeding stage is determined by 3 mortality components. (1) The female-to-larval survival probability is calculated using the relationships between inter-stadial mortalities (expressed as $k$-values) and climatic variables established by Randolph (1994, 1997). These relationships are site specific, i.e. the particular climatic variables shown to be critical, the partial regression coefficient of mortality on this variable and any additional partial regression coefficient on female tick densities all vary from site to site. This survival probability is assumed, for simplicity, to be independent of the total time between adult female ticks and their larval offspring feeding. (2) An additional density-independent mortality based on a constant daily rate is applied over the actual development period. (3) A second additional density-independent mortality, at a rather higher daily rate, is applied during the questing period. Finally, in equatorial sites where rainfall was shown to be the critical abiotic factor determining survival, an additional very high daily mortality was imposed on eggs and ticks developing during the dry season (rainfall $<5-10 \mathrm{~mm} /$ week).

Both the nymphs and the adults present in the model on any particular day are treated in an analagous way. Developmental periods are calculated and the 3 components of mortality applied as in the case of the larvae. Whereas the first mortality component (1, above) between adults and larvae is rarely density dependent, those of the larval-tonymphal and nymphal-to-adult stages are usually a function of the initial densities of larvae and nymphs respectively (Randolph, 1994, 1997). Since the operation of density dependence was detected through the analysis of field counts of ticks on hosts, the model uses the number of ticks present on any particular day on the hosts as the independent variable in its calculation of the appropriate mortality rates. There may also be a secondary abiotic factor determining this mortality component, according to a site- and stadial-specific partial regression coefficient.

Finally, the model applies diapause to ticks in the South African sites where this has been shown to be important (Rechav, 1981), according to an empirically derived rule (Randolph, 1997). All nymphs that would have given rise to adults after July each year are held over (i.e. diapause) and do not appear as adults until some time after November of the same 


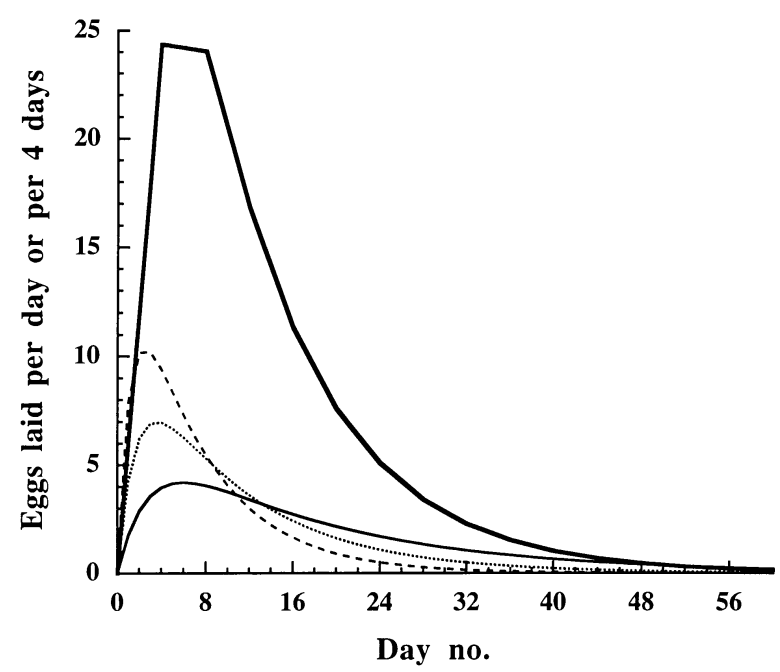

Fig. 2. The time-course of egg-laying by Rhipicephalus appendiculatus as included in the model, showing the numbers of eggs laid per day at $18^{\circ} \mathrm{C}$ (solid line), $21^{\circ} \mathrm{C}$ (dotted line) and $25^{\circ} \mathrm{C}$ (dashed line), and the numbers of eggs paid per 4 days at $21^{\circ} \mathrm{C}$ (heavy line) for comparison with empirical data from Branagan (1973a).

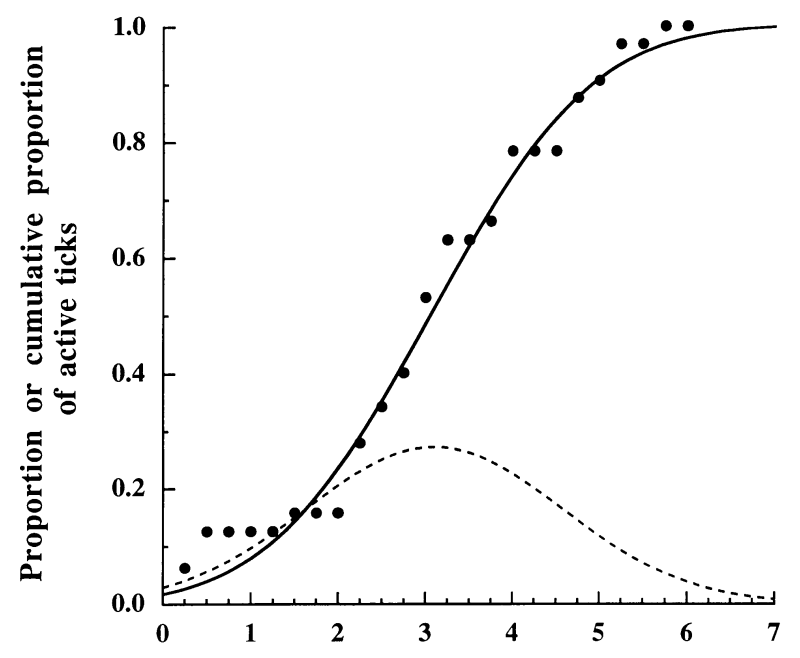

Time from first onset of tick activity, months

Fig. 3. Cumulative proportion of active female Rhipicephalus appendiculatus related to the time since first activity after diapause was recorded in experimental columns, in shade but otherwise under natural conditions in Zambia (data from Berkvens et al. (1995) Fig. 4). Also shown are the normal curve (dashed line) and cumulative normal curve (solid line) with the same mean and standard deviation ( $93 \pm 43$ days) as the observed data.

year. Berkvens et al. (1995) have shown that diapause does not end abruptly, but that diapausing $R$. appendiculatus in Zambia become active over extended periods of time of up to 5 months (Fig. 3). This behaviour was incorporated into the model by assuming a Gaussian random distribution of time to diapause cessation beyond 1 November each year, with the mean set 3-4 months after this date, and a standard deviation of about a third of the mean (with the rule, however, that diapause could never end before 1 November). The result of these assumptions is that post-diapause females appear on hosts from 1 November each year until possibly March or April of the following year, with a peak near the turn of the year. The total interstadial mortality from nymphs to adults applied at this stage in the model is composed of the same 3 components as described above. As the second component (density-independent mortality during development) is applied on a daily basis, it has a greater impact on the diapausing than non-diapausing individuals.

\section{Choice of parameter values}

The model (programmed in Quick BASIC) was run, its output was compared on-screen with the observed field data for each test site, and the parameters were varied until the fit improved (Table 1 gives the final chosen values). There are no estimates of absolute mortality rates or feeding probabilities for $R$. appendiculatus under completely natural field conditions, but the values were constrained to be biologically sensible and consistent with any available empirical data, and, in the absence of evidence to the contrary, to be as constant across sites as possible. Thus the observed partial regression coefficients determining the seasonal mortality indices, as derived from the field data, were preserved. The field data, however, give only relative, not absolute, estimates of the abundance of the different life-stages of the tick on the hosts. The re-scaling of the tick counts $(($ larvae +1$) \times 100$, (nymphs +1$) \times 10)$ applied by Randolph $(1994,1997)$ to ensure non-negative inter-stadial mortalities reflects this differential sampling efficiency, but does not necessarily correct for it sufficiently. The resulting mortality relationships are likely to show the correct sensitivity of mortality rates to the different independent variables selected, as reflected in the partial regression coefficients, but not their correct levels, as determined by the regression intercepts. Thus, in running the model, the value of the intercept of each inter-stadial mortality was adjusted to improve model performance (Table 1).

Estimates taken from field observations on survival periods of engorged ticks in Kenya (Branagan, $1973 b$ ) and Zambia (Pegram \& Banda, 1990) and unfed ticks in Zimbabwe (Short et al. 1989), all in containers (i.e. protected from predators), consistently show decreasing daily mortality rates as the life-cycle proceeds (larvae, 0.07-0.003; nymphs, 0.029-0.0028; adults, 0.011-0.0015). Although there was no obvious difference between the mortality rates of developing and questing ticks in these studies, intuitively it seems likely that questing ticks, exposed on the vegetation, will suffer higher mortality. The constant daily density-independent mortalities were therefore set according to this pattern 
Table 1. Input parameter values and variables for the population model for Rhipicephalus appendiculatus at 4 sites in equatorial and southern Africa

\begin{tabular}{|c|c|c|c|c|}
\hline & $\begin{array}{l}\text { Kirundo } \\
\text { Burundi }\end{array}$ & $\begin{array}{l}\text { B's Fort } \\
\text { Uganda }\end{array}$ & $\begin{array}{l}\text { Gulu } \\
\text { S. Africa }\end{array}$ & $\begin{array}{l}\text { B'sfield } \\
\text { S. Africa }\end{array}$ \\
\hline Egg-laying parameters, $r 1$ and $r 2$ & $0 \cdot 5,0 \cdot 1$ & $0 \cdot 7,0 \cdot 15$ & $0 \cdot 5,0 \cdot 1$ & $0 \cdot 3,0 \cdot 06$ \\
\hline $\begin{array}{l}\text { Diapause: start and end months emergence, } \\
\text { mean day and s.D. }\end{array}$ & $\mathrm{n} / \mathrm{a}$ & $\mathrm{n} / \mathrm{a}$ & $\begin{array}{l}6,11 \\
105,30\end{array}$ & $\begin{array}{l}6,11 \\
105,30\end{array}$ \\
\hline \multicolumn{5}{|l|}{ Daily feeding probability } \\
\hline Larvae & $0 \cdot 05$ & $0 \cdot 04$ & $0 \cdot 04$ & $0 \cdot 05$ \\
\hline Nymphs & $0 \cdot 1$ & $0 \cdot 09$ & $0 \cdot 1$ & $0 \cdot 1$ \\
\hline Adults & $0 \cdot 15$ & $0 \cdot 14$ & $0 \cdot 14$ & $0 \cdot 14$ \\
\hline \multicolumn{5}{|l|}{ Constant daily mortality } \\
\hline \multicolumn{5}{|l|}{ During development* } \\
\hline Adults-larvae & $0 \cdot 015$ & $0 \cdot 02$ & $0 \cdot 02$ & $0 \cdot 015$ \\
\hline Larvae-nymphs & $0 \cdot 006$ & $0 \cdot 01$ & $0 \cdot 01$ & $0 \cdot 01$ \\
\hline Nymphs-adults & $0 \cdot 003$ & $0 \cdot 005$ & $0 \cdot 006$ & $0 \cdot 005$ \\
\hline \multicolumn{5}{|l|}{ During questing } \\
\hline Larvae & $0 \cdot 05$ & $0 \cdot 05$ & $0 \cdot 05$ & $0 \cdot 06$ \\
\hline Nymphs & $0 \cdot 02$ & $0 \cdot 03$ & $0 \cdot 03$ & $0 \cdot 04$ \\
\hline Adults & $0 \cdot 005$ & $0 \cdot 01$ & $0 \cdot 01$ & $0 \cdot 02$ \\
\hline \multicolumn{5}{|l|}{ Drought daily mortality } \\
\hline rain threshold (mm/week) & 5 & 10 & $\mathrm{n} / \mathrm{a}$ & $\mathrm{n} / \mathrm{a}$ \\
\hline Eggs & $0 \cdot 1$ & $0 \cdot 25$ & & \\
\hline Larvae & $0 \cdot 01$ & $0 \cdot 15$ & & \\
\hline Nymphs & $0 \cdot 04$ & $0 \cdot 15$ & & \\
\hline Adult & 0 & 0 & & \\
\hline \multicolumn{5}{|l|}{$\begin{array}{l}\text { Variable density-independent interstadial } \\
\text { mortality }\end{array}$} \\
\hline \multicolumn{5}{|l|}{ Adults-larvae } \\
\hline Factor & Rainfall & Rainfall & Min. RH & Min. temp. \\
\hline Intercept & $-1 \cdot 5$ & $1 \cdot 5$ & $-0 \cdot 5$ & $2 \cdot 2$ \\
\hline Slope & $-0 \cdot 0563$ & $-0 \cdot 039$ & $0 \cdot 0255$ & $-0 \cdot 104$ \\
\hline 2nd factor (no. adult), slope & 0.992 & & & \\
\hline \multicolumn{5}{|l|}{ Density-dependent interstadial mortality } \\
\hline \multicolumn{5}{|l|}{ Larvae-nymphs } \\
\hline Intercept & $-4 \cdot 0$ & $-2 \cdot 5$ & $-1 \cdot 8$ & $-2 \cdot 5$ \\
\hline Slope & $0 \cdot 900$ & $0 \cdot 585$ & $0 \cdot 387$ & $0 \cdot 387$ \\
\hline 2nd factor (rain), slope & $-0 \cdot 03$ & $-0 \cdot 01$ & & \\
\hline \multicolumn{5}{|l|}{ Nymphs-adult } \\
\hline Intercept & $-3 \cdot 5$ & $-3 \cdot 5$ & $-2 \cdot 6$ & $-3 \cdot 0$ \\
\hline Slope & $1 \cdot 21$ & $1 \cdot 281$ & $1 \cdot 24$ & $1 \cdot 24$ \\
\hline 2nd factor (rain), slope & $-0 \cdot 01$ & & & \\
\hline
\end{tabular}

* The development periods, $y$, depend on mean ambient temperature according to the following empirical relationships (Randolph (1997): adult to larva, $y=283.806 \times 10^{-0.026 x}$; nymph to adult, $y=318 \cdot 634 \times 10^{-0.033 x}$; larva to nymph, $y=$ $193.409 \times 10^{-0.036 x}$, where $x$ is the mean $((\min .+\max ) / 2$.$) temperature.$

(Table 1). If the later tick life-stages are physically and physiologically less vulnerable to adverse abiotic conditions (Randolph, 1993), these ticks can spend longer questing at the top of the vegetation thus increasing their daily feeding probability relative to earlier stages. Estimates for Ixodes ricinus in the UK suggest this to be the case (Randolph \& Steele, 1985).

The parameter values for the final models varied very little from site to site, and only in ways that were consistent with the known variation in climatic conditions. For example, the best-fit constant daily mortality rates were slightly lower at Kirundo (Burundi) than at the other equatorial site, Baker's Fort (Uganda), perhaps because Kirundo was cooler, especially during and just after the dry season. This constancy suggests that the geographical variation in seasonal patterns is determined almost wholly by abiotic factors, firstly temperature that drives the development rates and secondly the factor critical for the tick's survival, rainfall near the equator and relative humidity or minimum temperature in South Africa.

\section{Validation and sensitivity analysis}

In selecting the final model, the overall aim was to mimic (a) the observed pattern of seasonality, judged visually and also statistically by the $R^{2}$ value of the regressions of the predicted versus observed monthly log numbers of each stage of tick; (b) the observed (i.e. log scale) variation of each tick life-stage, judged by how closely the slopes of the above regressions approximate to $1 ;$ (c) the different relative stabilities

\section{CAmbridge JDURNALS}



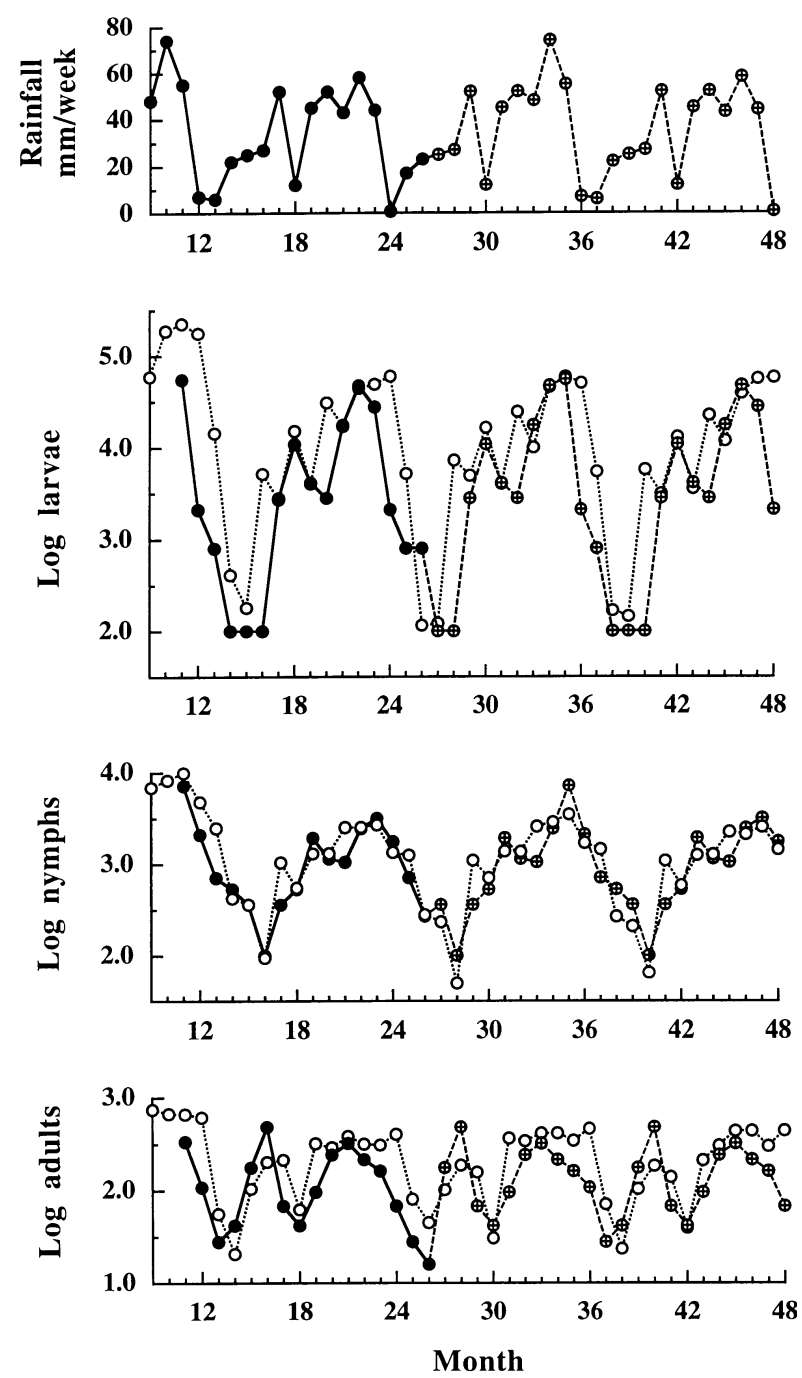

Fig. 4. Baker's Fort, Uganda. Seasonal variation in rainfall and the mean number of Rhipicephalus appendiculatus larvae, nymphs and adults per host observed ( ) and predicted by the model $(\bigcirc)$. For the observations, month 11 is November 1977 (from Kaiser et al. 1991), and the observed pattern is repeated $(\oplus)$ for comparison with predictions up to month 48 . Observed larvae $\times 100$, observed nymphs $\times 10$.

of each stage; (d) the observed relationships between interstadial mortality rates and population density. For example, a nymphal population that shows less variation on a $\log$ scale than the larval population that gave rise to it, must have experienced some density-dependent mortality in the interim. The amount of such mortality could be adjusted in the model by varying the value of the intercept of the density-dependent larval-nymphal mortality. Increasing the mortality on one life-stage always has consequences for other life-stages as well as the one directly affected, so that, for example, a reduced nymphal population is less likely than before to experience density-dependent mortality (or experiences less of it) as it develops to the next, adult stage. For the model output to show the same mortality relationships as those calculated from the field data is
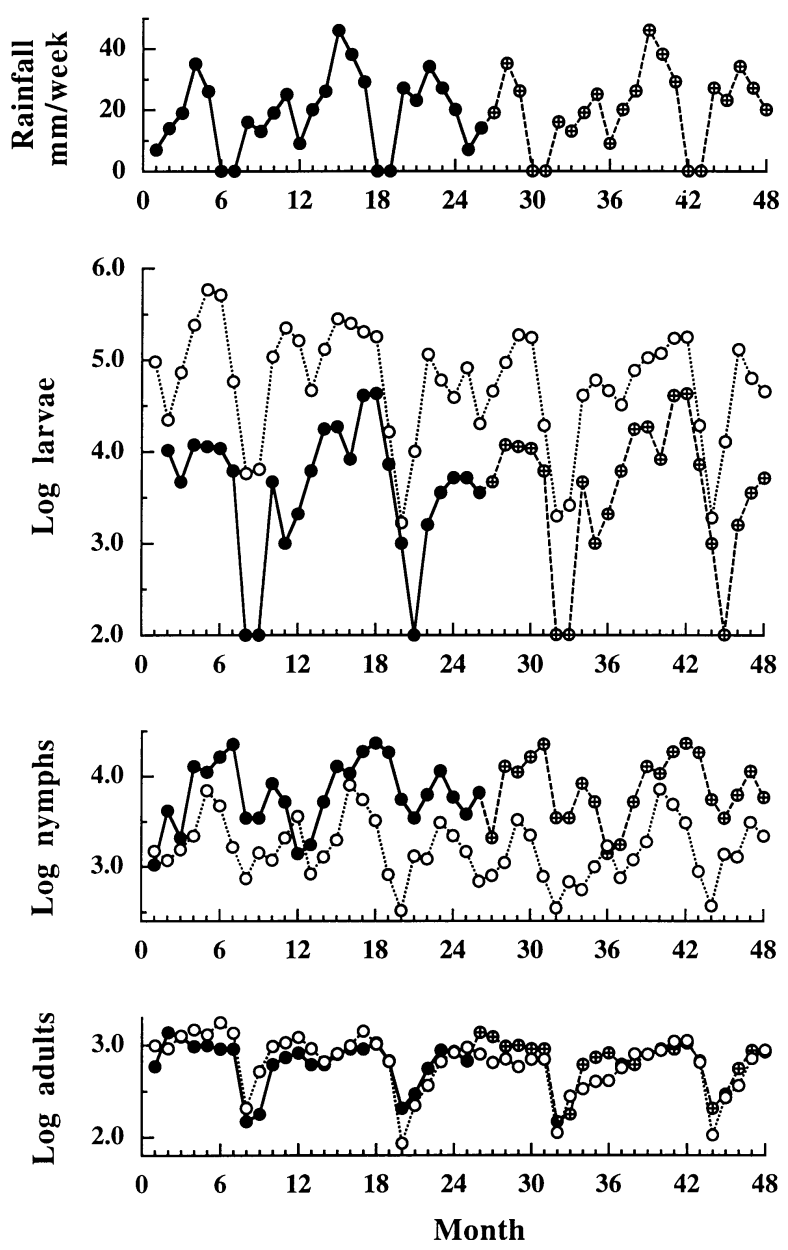

Fig. 5. Kirundo, Burundi. Seasonal variation in rainfall and the mean number of Rhipicephalus appendiculatus larvae, nymphs and adults per host observed $(\mathbf{O})$ and predicted by the model $(\bigcirc)$. For the observations, month 1 is January 1980 (from Kaiser et al. 1988), and the observed pattern is repeated $(\oplus)$ for comparison with predictions up to month 48 . Observed larvae $\times 100$, observed nymphs $\times 10$.

by no means trivial, as the various distributions included within the model (e.g. of oviposition, development time, feeding intervals and diapause completion) all had to be estimated from barely adequate data sets, and it is these distributions which to a large extent determine the time-delays that Randolph $(1994,1997)$ incorporated into the various regression calculations of mortality rates in the field data.

Of less significance in validating the model are matches between the observed and predicted absolute levels of abundance of each stage, because of the problem of differential sampling efficiency referred to above. Despite the likelihood that such sampling biases varied between sites (studies), for comparability all the actual field counts of larvae have been multiplied by 100 , and those of nymphs by 10 , but this may correct for the under-counting of immature stages either by too much or too little, resulting in some mismatches between the re-scaled 

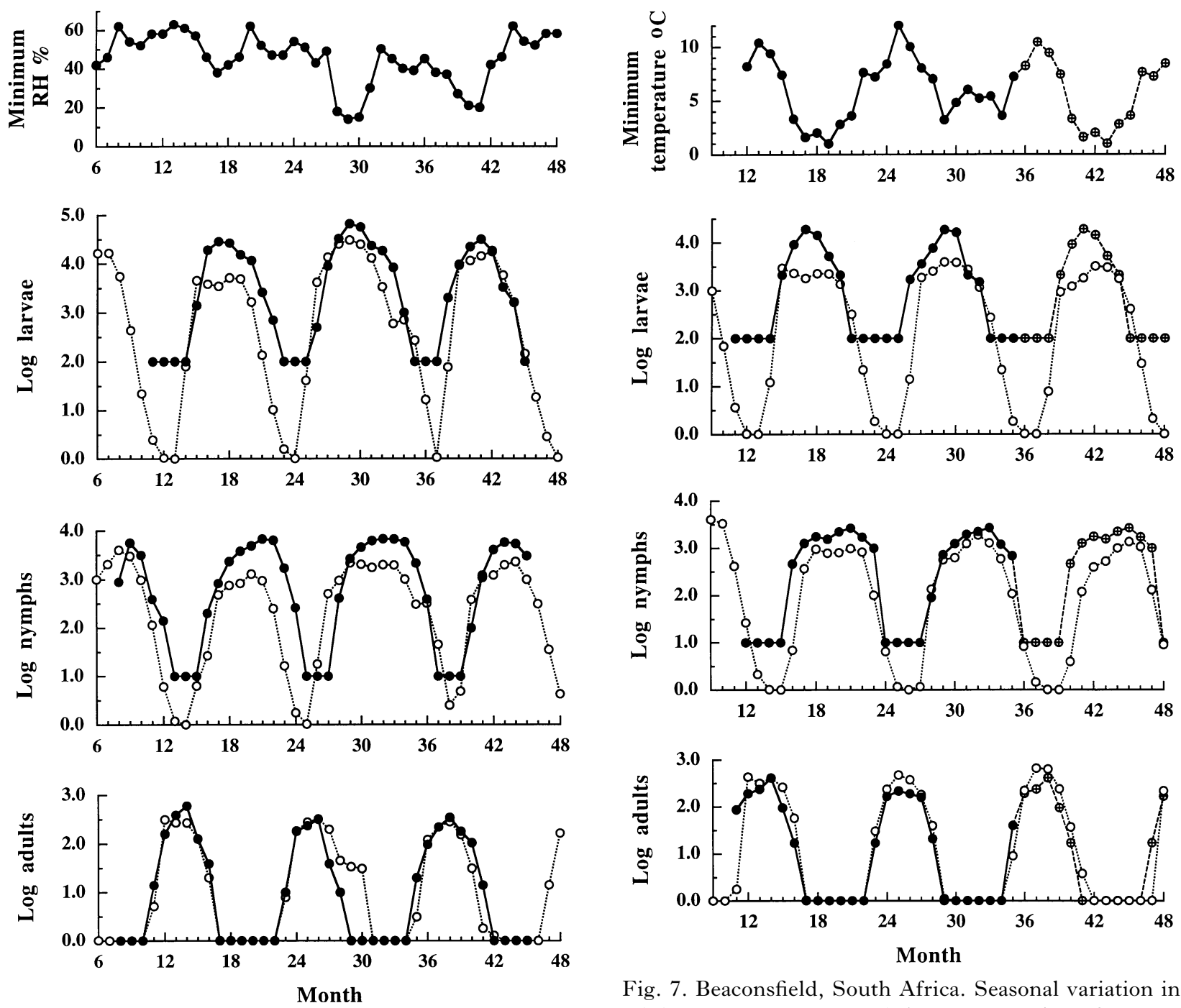

Fig. 6. Gulu, South Africa. Seasonal variation in minimum relative humidity and the mean number of Rhipicephalus appendiculatus larvae, nymphs and adults per host observed $(\bigcirc)$ and predicted by the model $(\bigcirc)$. For the observations, month 6 is June 1975 (from Rechav, 1981). Observed larvae $\times 100$, observed nymphs $\times 10$.

observed and the predicted. Of more importance is that the predictions should reflect the biologically correct relative numbers of each stage, with the expectation that predicted adult numbers will most closely match the field counts.

The sensitivity of the model outputs to the precise value of each parameter value was tested by halving and doubling each parameter value for each tick stage in turn, and then for all stages together. The effects were examined by regressing the monthly numbers of ticks predicted by the changed model against those predicted by the final chosen model, over 50 months of model output. The greater the impact of changing each parameter value, the more the slope and $R^{2}$ value of each regression would depart from $1 \cdot 0$, as the seasonal variation in tick numbers and its pattern, respectively, are altered.

Fig. 7. Beaconsfield, South Africa. Seasonal variation in minimum temperature and the mean number of Rhipicephalus appendiculatus larvae, nymphs and adults per host observed $(\bigcirc)$ and predicted by the model $(\bigcirc)$. For the observations, month 11 is November 1977 (from Rechav, 1981), and the observed pattern is repeated $(\oplus)$ for comparison with predictions up to month 48 .

Observed larvae $\times 100$, observed nymphs $\times 10$.

Finally, the model was used to predict the seasonal dynamics of populations of ticks from a site other than those of the original population analyses. Here, only adults and nymphs had been counted (which is why full population analysis was not possible), against which the model's predictions were tested. The site chosen was Ukunda, on the Kenyan coast $\left(39^{\circ} 34^{\prime} \mathrm{E}, 4^{\circ} 17^{\prime} \mathrm{S}\right)$ (Newson, 1978), because the climatic conditions here are rather different from those at any of the 11 sites previously explored in detail, making the test particularly stringent.

\section{RESULTS}

\section{Seasonal variation in tick numbers}

Model predictions and the assays of their validity and sensitivity are presented for 4 test sites: Baker's 

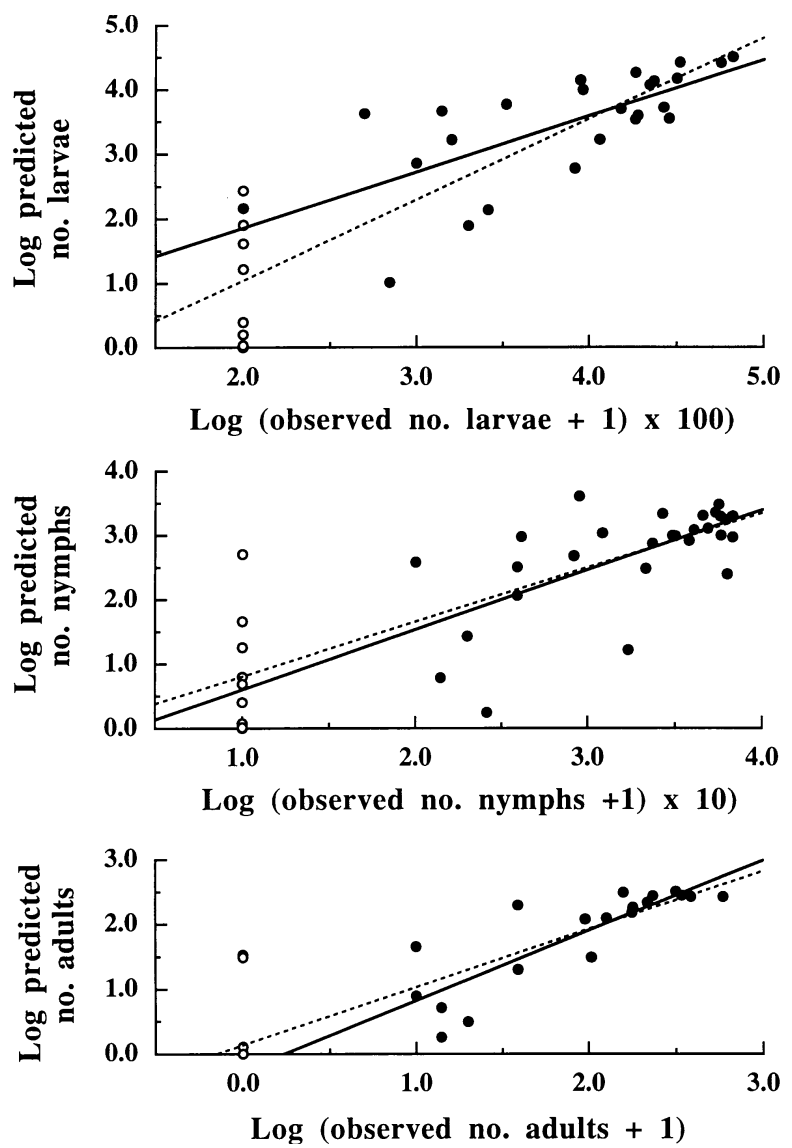

Fig. 8. Gulu, South Africa. Regressions of modelpredicted versus observed log monthly numbers of Rhipicephalus appendiculatus larvae, nymphs and adults, including (dashed line) and excluding (solid line) months of zero counts of field ticks $(\bigcirc)$. The statistics of these regressions, and of those at the other 3 test sites, are presented in Table 2 .
Fort (Patiko) in northern Uganda, and Kirundo in Burundi, as examples of equatorial sites where rainfall is the critical abiotic factor, but where the seasonality patterns of $R$. appendiculatus differ somewhat; Gulu and Beaconsfield farms in South Africa, where the critical abiotic factor is minimum relative humidity and minimum temperature respectively. For each site, the model has captured the essential features of the tick's seasonal dynamics in considerable detail (Figs 4-7). As the observed larvae are plotted as $\log ((n+1) \times 100))$, and observed nymphs as $(\log ((n+1) \times 10))$, zero counts of these stages appear as $2 \cdot 0$ and 1.0 respectively. These minimum observed levels probably represent the lower threshold of detectability rather than complete absences of immature stages on cattle. For South Africa, the model predicts an absence of larvae and nymphs for 1 or 2 months of the year, and very low numbers of both stages for 3-4 months, coinciding with the recorded absences. The periods of low numbers observed at Beaconsfield (Fig. 7) are longer than those at Gulu (Fig. 6), and the model reflects this. In contrast, adults are predicted to be absent from cattle for almost exactly the same extended periods as recorded. For equatorial Africa, the model captures the observed sudden marked decreases in numbers of all 3 stages soon after each dry season, but never predicts zero ticks of any stage at any time of the year. Least well matched by the model is the observed pattern for nymphs at Kirundo (Fig. 5); elements of this pattern, specifically the second marked decline in December/January, could not be explained by the original population analysis either (Randolph, 1994).

In comparing the fit of the predictions to the observations statistically, the extended periods of

Table 2. Model validation: correlations of the monthly numbers of feeding Rhipicephalus appendiculatus observed at 4 sites in equatorial and South Africa and predicted by the population model

\begin{tabular}{|c|c|c|c|c|c|c|c|c|c|}
\hline \multirow[b]{2}{*}{ Site } & \multirow{2}{*}{$\begin{array}{l}\text { Stage of } \\
\text { tick }\end{array}$} & \multicolumn{4}{|c|}{ Full observed data set } & \multicolumn{4}{|c|}{ Omitting observed zero counts } \\
\hline & & $n$ & $b \dagger$ & $t$ valuef & $\% R^{2}$ & $n$ & $b \dagger$ & $t$ valuef & $\% R^{2}$ \\
\hline \multicolumn{10}{|l|}{ South Africa } \\
\hline \multirow[t]{3}{*}{ Gulu } & Larvae & 35 & $1 \cdot 247$ & $1 \cdot 019$ & $74 \cdot 4 * * *$ & 25 & $0 \cdot 863$ & $0 \cdot 576$ & $50 \cdot 2 * * *$ \\
\hline & Nymphs & 38 & $0 \cdot 848$ & $0 \cdot 895$ & $64 \cdot 4 * * *$ & 29 & 0.933 & $0 \cdot 249$ & $42 \cdot 3 * * *$ \\
\hline & Adults & 38 & $0 \cdot 896$ & $0 \cdot 686$ & $82 \cdot 1 * * *$ & 19 & $1 \cdot 083$ & $0 \cdot 297$ & $70 \cdot 7 * * *$ \\
\hline \multirow[t]{3}{*}{ Beaconsfield } & Larvae & 25 & $1 \cdot 301$ & $0 \cdot 989$ & $71 \cdot 2 * * *$ & 13 & $0 \cdot 680$ & $0 \cdot 837$ & $20 \cdot 9$ \\
\hline & Nymphs & 24 & $1 \cdot 107$ & $0 \cdot 446$ & $85 \cdot 8 * * *$ & 16 & $1 \cdot 097$ & $0 \cdot 261$ & $43 \cdot 8 * *$ \\
\hline & Adults & 25 & $1 \cdot 014$ & $0 \cdot 063$ & $86 \cdot 7 * * *$ & 13 & 0.986 & $0 \cdot 034$ & $38 \cdot 0 *$ \\
\hline \multicolumn{10}{|l|}{ Uganda } \\
\hline \multirow[t]{3}{*}{ Baker's Fort } & Larvae & 16 & $0 \cdot 749$ & $0 \cdot 947$ & $47 \cdot 3 * *$ & & & & \\
\hline & Nymphs & 16 & 0.978 & $0 \cdot 097$ & $81 \cdot 2 * * *$ & & & & \\
\hline & Adults & 16 & $0 \cdot 702$ & $1 \cdot 362$ & $49 \cdot 3 *$ & & & & \\
\hline \multicolumn{10}{|l|}{ Burundi } \\
\hline \multirow[t]{3}{*}{ Kirundo } & Larvae & 25 & $0 \cdot 607$ & $2 \cdot 537^{*}$ & $56 \cdot 7 * * *$ & & & & \\
\hline & Nymphs & 26 & $0 \cdot 326$ & $4 \cdot 19 * * *$ & $13 \cdot 8$ & & & & \\
\hline & & 25 & $0 \cdot 901$ & $0 \cdot 642$ & $68 \cdot 6 * * *$ & & & & \\
\hline
\end{tabular}

$\uparrow$ Slope of regression of predicted versus observed monthly tick numbers.

\pm Test of the difference of slope from $1 \cdot 0$. * $P<0 \cdot 05$; ** $P<0 \cdot 01$; *** $P<0 \cdot 001$. 


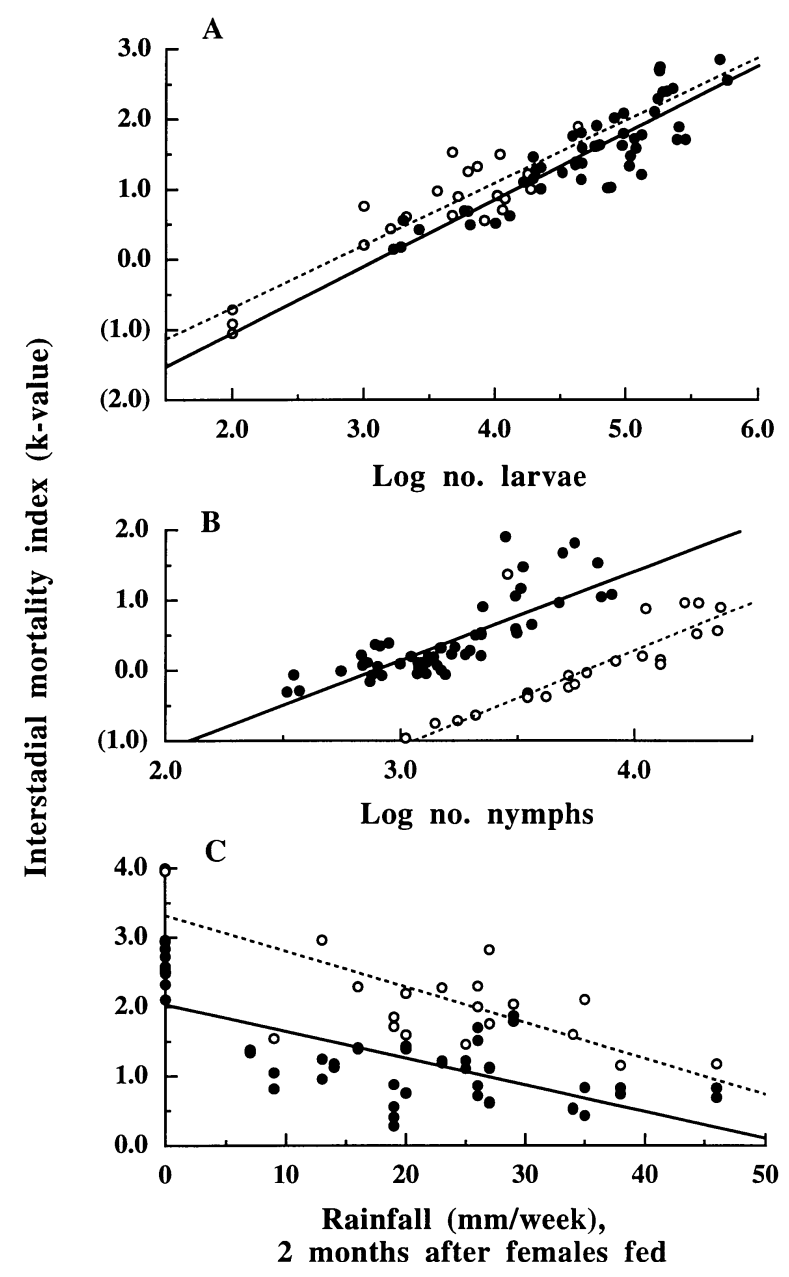

Fig. 9. Kirundo, Burundi. Interstadial mortality relationships for Rhipicephalus appendiculatus. Densitydependent relationships between the index of mortality (A) from larvae to nymphs and the log number of larvae, and (B) from nymphs to adults and the log number of nymphs, observed $(\bigcirc)$ and predicted by the model (-). (C) The relationship between the index of mortality from adults to larvae and rainfall 2 months after the females had fed, observed $(O)$ and predicted by the model ( ). The statistics of these regressions, and of those at the other 3 test sites, are presented in Table 3 . In all cases only the principal single variable regression is presented, omitting any additional partial regressions.

zero counts in South Africa potentially have a major effect on the correlations (Fig. 8, for an example at Gulu). When all the zero counts are included, the slopes are very little different from those of regressions that omit all observed zero counts, but the $R^{2}$ values are much increased (Table 2). Even when all zero counts, and therefore a significant element of the seasonal pattern, are omitted, the model explains $42-71 \%$ of the remaining observed variation in tick abundance at Gulu. At Beaconsfield, when the seasonal low periods are omitted, statistically the model fit seems much less good $\left(R^{2}=21-44 \%\right.$ compared with $71-87 \%$ for the full seasonal pattern, Table 2), because tick numbers varied very little during the periods of high tick abundance, and single monthly mis-matches (month 26 for larvae, month 16 for nymphs, month 11 for adults, Fig. 7) have a large impact on $R^{2}$ values. At equatorial sites, where it is unnecessary to exclude the brief period of zero counts of larvae from the correlations, the model explains $47-81 \%$ of the observed variation in tick numbers, except for nymphs at Kirundo, reflecting the rather poor visual match noted above. Kirundo was the only site for which the slopes of the regressions were low, especially for nymphs; in no other case were the slopes significantly different from $1 \cdot 0$, confirming that the model has captured the observed seasonal variation in the numbers of each tick stage.

\section{Mortality relationships}

The mortality relationships of the model populations, calculated in exactly the same way as in the original field population analyses (Randolph, 1994, 1997), were similar both qualitatively and quantitatively to those of the field populations (Fig. 9, Table 3). Strong density dependence operated during the larval-nymphal and nymphal-adult stages. The model density dependence was less intense than observed during the larval-nymphal stage at Beaconsfield, largely because the annual peak of the modelled larval population was flatter than the observed peak (Fig. 7), giving more constant high levels of both larval numbers and larvalnymphal mortality indices. During the adult-larval stage, mortality was density independent; only at Beaconsfield did the model fail to show the same relationship between this mortality and the critical abiotic factor as was observed in the field population. Again, this arose from the model's flat-topped peak numbers of larvae, giving unnaturally high estimates of mortality after females had fed (and laid their eggs) when minimum temperatures were high ( $>8{ }^{\circ} \mathrm{C}$, Dec.-Feb.), which is associated with low mortality in the field (Randolph, 1997).

\section{Sensitivity analyses}

The final chosen model proved to be remarkably robust. Changes in the amount of seasonal variation in the numbers of each stage (measured by the departure from 1.0 of the slope of the regression of modified versus chosen model output, Figs $10 \mathrm{~A}$ and $11 \mathrm{~A}$ ) and in the pattern of that variation (measured by the reduction from unity in $R^{2}$ value for the same regression, Figs $10 \mathrm{~B}$ and $11 \mathrm{~B}$ ) rarely exceeded $20 \%$ and were usually less than $5 \%$. The model was most sensitive to changes in the regression coefficients determining the density-dependent interstadial mortality indices (parameter numbers 18 and 20, Figs 10 and 11), whose chosen values were most reliable, 
Table 3. Model validation: interstadial mortality relationships for Rhipicephalus appendiculatus at 4 sites in equatorial and South Africa: as observed, as input to, and as output from the population model

\begin{tabular}{|c|c|c|c|c|c|c|c|c|c|}
\hline \multirow[b]{2}{*}{ Site } & \multirow{2}{*}{$\begin{array}{l}\text { Interstadial } \\
\text { period }\end{array}$} & \multirow{2}{*}{$\begin{array}{l}\text { Independent } \\
\text { variable }\end{array}$} & \multirow{2}{*}{$\begin{array}{l}\text { Model } \\
\text { input } \\
b \dagger\end{array}$} & \multicolumn{3}{|c|}{ Observed } & \multicolumn{3}{|c|}{ Model output } \\
\hline & & & & $n$ & $b \uparrow$ & $\% R^{2}$ & $n$ & $b \uparrow$ & $\% R^{2}$ \\
\hline \multicolumn{10}{|l|}{ South Africa } \\
\hline \multirow[t]{3}{*}{ Gulu } & Larva-nymph & Log larvae & $0 \cdot 387$ & 22 & $0 \cdot 383$ & $46 \cdot 4 * * *$ & 44 & $0 \cdot 290$ & $76 \cdot 4 * * *$ \\
\hline & Nymph-adult & Log nymphs & $1 \cdot 240$ & 14 & $1 \cdot 337$ & $77 \cdot 4 * * *$ & 29 & $1 \cdot 001$ & $65 \cdot 1 * * *$ \\
\hline & Adult-larva & Min. \% RH & $0 \cdot 026$ & 22 & $0 \cdot 027$ & $44 \cdot 0 * * *$ & 28 & $0 \cdot 019$ & $19 \cdot 4 *$ \\
\hline \multirow[t]{3}{*}{ Beaconsfield } & Larva-nymph & Log larvae & $0 \cdot 387$ & 13 & $0 \cdot 585$ & $52 \cdot 4 * *$ & 42 & $0 \cdot 109$ & $70 \cdot 4 * * *$ \\
\hline & Nymph-adult & Log nymphs & $1 \cdot 240$ & 6 & $2 \cdot 003$ & $74 \cdot 1 *$ & 27 & $0 \cdot 829$ & $61 \cdot 2 * * *$ \\
\hline & Adult-larva & Min. temp. & $-0 \cdot 104$ & 11 & $-0 \cdot 162$ & $58 \cdot 5 * *$ & 41 & $0 \cdot 012$ & $0 \cdot 002$ \\
\hline \multicolumn{10}{|l|}{ Uganda } \\
\hline \multirow[t]{3}{*}{ Baker's Fort } & Larva-nymph & Log larvae & $0 \cdot 585$ & 15 & $0 \cdot 591$ & $91 \cdot 2 * * *$ & 50 & $0 \cdot 512$ & $75.9 * * *$ \\
\hline & Nymph-adult & Log nymphs & $1 \cdot 281$ & 14 & $1 \cdot 281$ & $66 \cdot 8 * * * *$ & 50 & $0 \cdot 805$ & $50 \cdot 0 * * *$ \\
\hline & Adult-larva & Rainfall & -0.039 & 13 & $-0 \cdot 039$ & $41 \cdot 6 *$ & 48 & $-0 \cdot 034$ & $42 \cdot 9 * * *$ \\
\hline \multicolumn{10}{|l|}{ Burundi } \\
\hline \multirow[t]{3}{*}{ Kirundo } & Larva-nymph & Log larvae & $0 \cdot 900$ & 23 & $0 \cdot 891$ & $80 \cdot 8 * * *$ & 50 & 0.953 & $75 \cdot 5 * * *$ \\
\hline & Nymph-adult & Log nymphs & $1 \cdot 210$ & 22 & $1 \cdot 360$ & $87 \cdot 4 * * *$ & 50 & $1 \cdot 279$ & $70 \cdot 6 * * *$ \\
\hline & Adult-larva & Rainfall & $-0 \cdot 056$ & 21 & $-0 \cdot 052$ & $60 \cdot 1 * * *$ & 48 & $-0 \cdot 038$ & $48 \cdot 4 * * *$ \\
\hline
\end{tabular}

$\uparrow$ Slope of the regression of interstadial mortality indices against either the identified critical abiotic factor, or the density of the feeding stage immediately preceding the mortality. ${ }^{*} P<0 \cdot 05 ; * * P<0 \cdot 01$; $* * * P<0 \cdot 001$.

having been derived from field data. In South Africa, the pattern of emergence from diapause (parameter 22, Fig. 11) was also critical; both a more rapid activation of adults (mean \pm s.D. day of emergence $=$ $75 \pm 15$ days after 1 November) and a more gradual activation ( $135 \pm 60$ days after 1 November) had a marked effect on the model output. Also, doubling the daily mortality rate acting on all 3 development stages (parameter 12, Fig. 11) reduced seasonal peak numbers of all ticks. Near the equator, the major seasonal variation is caused by drought-induced mortality (Randolph, 1994); correspondingly, changing the amount of this mortality, especially that acting on adults (parameter 15) or on all 3 stages (parameter 16) had a marked effect (Fig. 10 A).

\section{Predicting the partly known}

The model was able to predict the seasonal patterns of nymphs and adults at Ukunda, Kenya, with acceptable accuracy (Fig. 12), but only when 2 slight modifications in the parameters were introduced. At Ukunda, the very high maximum temperatures (daily mean of over $32{ }^{\circ} \mathrm{C}$ recorded nearby at Mombasa; HMSO (1958)) during the dry season, followed by an extremely abrupt period of heavy rainfall, apparently had adverse effects on tick survival. Best fits between the model output and observations were achieved by including 2 additional partial regression coefficients (1) relating adult-larval and nymphal-adult interstadial mortality indices positively to the maximum temperature 1 month after adults and nymphs fed, and (2) relating the larval-nymphal mortality positively (rather than negatively) to the rainfall 1 month after larvae had fed. These effects have been identified elsewhere: at Mwanza, Tanzania, where temperatures are also very high, maximum temperatures were shown to be significantly correlated with mortality; at Gihofi, Burundi, questing nymphs also survived poorly in high rainfall (Randolph, 1994), another example of high mortality under conditions that are too wet rather than too dry (see Introduction section). Apart from these modifications, the model was the same as those for the other equatorial sites. Parameter values for feeding probabilities and daily mortality rates during development and questing were the same as at Baker's Fort, Uganda (see Table 1); additional daily mortality when rainfall $<5 \mathrm{~mm} /$ week, eggs $0 \cdot 15$, larvae $0 \cdot 10$ and nymphs $0 \cdot 075$; adult-larval interstadial mortality $=-3.75-(0.06 \times$ rainfall $)+$ $(0.98 \times \log$ females $)+(0.12 \times \max$. temp. $) ;$ larvalnymphal interstadial mortality $=-3.75+(0.85 \times \log$ larvae $)+(0.013 \times$ rainfall $) ; \quad$ nymphal-adult interstadial mortality $=-5 \cdot 0+(0 \cdot 8 \times \log$ nymphs $)-$ $(0 \cdot 015 \times$ rainfall $)+(0 \cdot 13 \times \max$. temp. $)$. Regressions of predicted versus observed log monthly numbers at Ukunda gave slopes of 0.710 and 0.838 , and explained $71 \%$ and $76 \%$ of the seasonal variation in numbers, for nymphs and adults respectively.

\section{DISCUSSION}

The utility of a model depends on its robustness and therefore its applicability under a wide range of conditions. The generic population model for $R$. appendiculatus presented here has proved to be robust on 2 major counts. First, the same form of the model, with very similar specific parameter values, correctly predicts the very different patterns of 
A

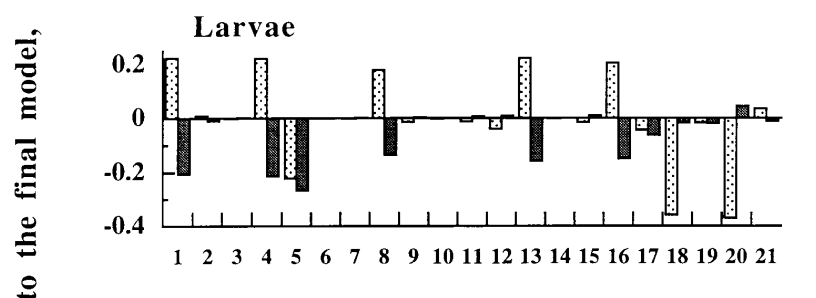

B
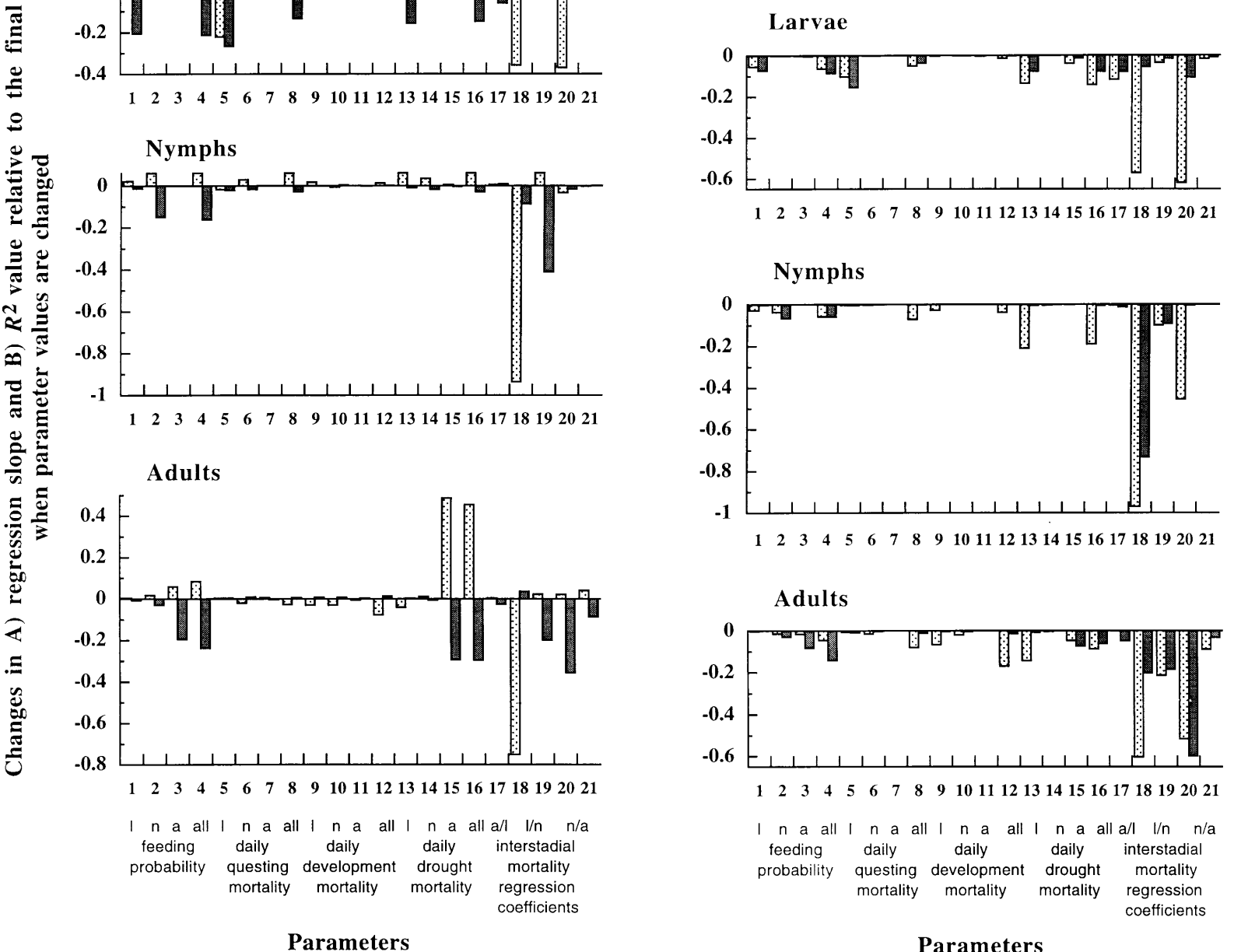

Fig. 10. Kirundo, Burundi. Results of sensitivity analysis. Changes in (A) regression slopes and (B) $R^{2}$ values relative to the final model, when parameter values are doubled (stippled) or halved (shaded). Parameter codes: $1-4$, feeding probabilities for larvae, nymphs, adults and all 3 stages; daily mortality rates, 5-8 during questing, 9-12 during development, and 13-16 during periods of drought, for larvae, nymphs, adults and all 3 stages; interstadial mortality regression coefficients, 17 for adult-larval, 18 and 19 for larval-nymphal and 20 and 21 for nymphal-adult periods (including partial regressions, see Table 1 ). In the case of parameter number 20 , the value was multiplied by 1.5 or by $0 \cdot 75$.

seasonality over virtually the complete north-south range of $R$. appendiculatus, from northern Uganda to the Cape of South Africa. The only changes needed as one moves south from tropical equatorial regions to increasingly temperate regions, is the insertion of a diapause term and the lessening of any extra drought-induced mortality. Secondly, once the correct combination of parameter values is found, the model is remarkably insensitive to the precise value of any one parameter. This allows the model to be used even when many of the daily rates of mortality and feeding can only be roughly estimated, as indeed they are here. The model is most sensitive to changes in the regression coefficients for the densitydependent interstadial mortality indices. They were derived from field data for the test sites presented here, and therefore, of all the parameter values, are most likely to be realistic. For sites where such estimates cannot be made, (as at Ukunda, see above) the general patterns apparent from the larger data set from 11 sites may act as a guide (Randolph, 1997, Table 2); for the nymphal-adult interstadial mortality, the density-dependent regression coefficient is very high throughout the tick's range (mean \pm 1 s.E. $=1 \cdot 200 \pm 0 \cdot 140, n=10$ ), while for the larvalnymphal mortality, the regression coefficient is lower in southern Africa $(0.403 \pm 0.069, n=4)$ than in equatorial Africa $(0 \cdot 794 \pm 0 \cdot 061, n=7)$. The critical climatic factor that determines the adult-larval mortality is geographically variable, although in equatorial regions it appears always to be some measure of moisture availability, for which rainfall is a useable index. Once the relationships between the relevant abiotic factor and satellite imagery have 
A

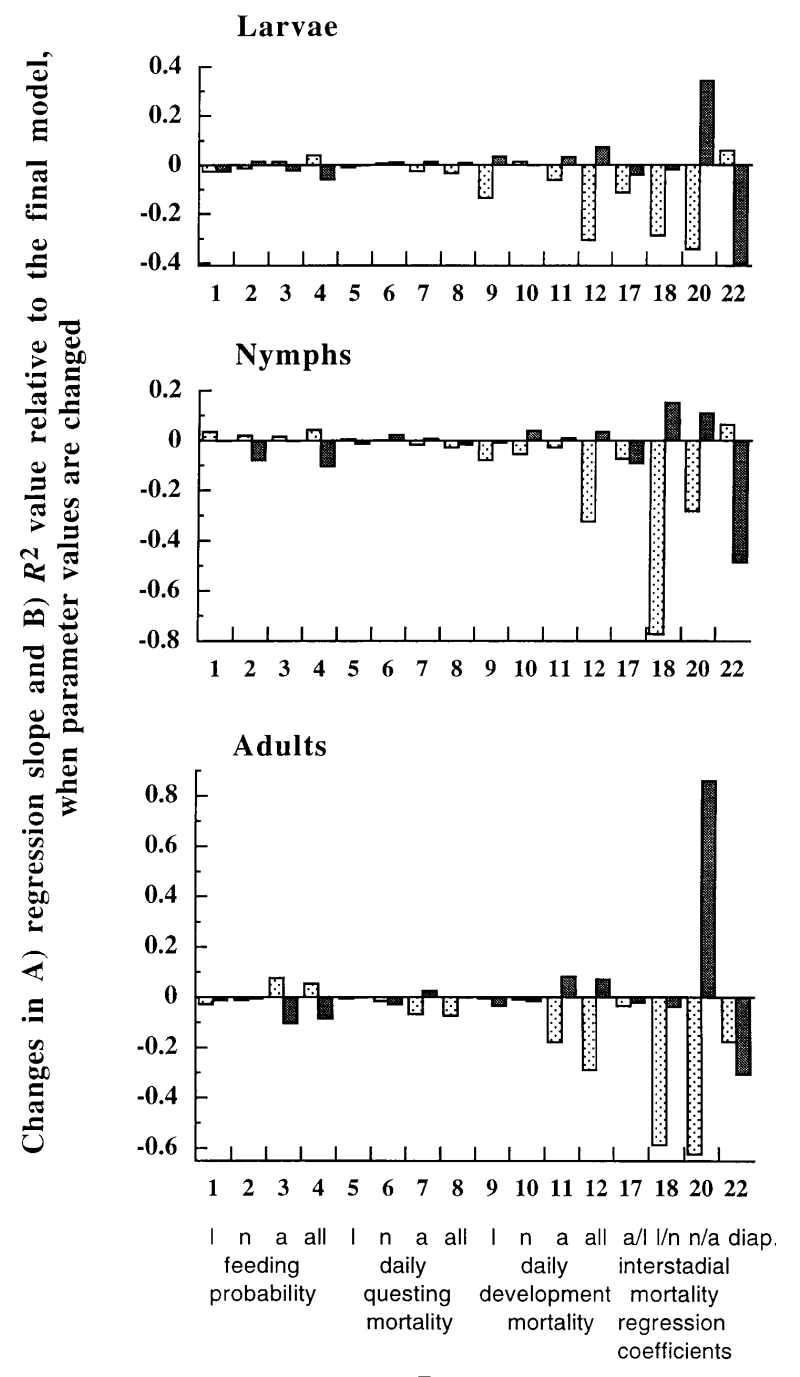

Parameters

B

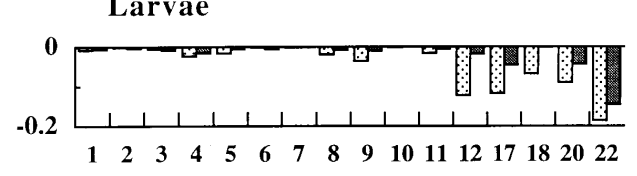

Nymphs

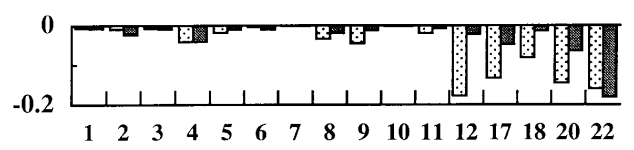

Adults

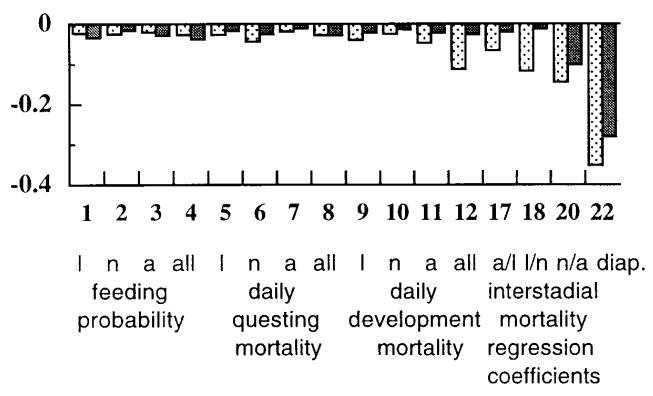

Parameters

Fig. 11. Gulu, South Africa. Results of sensitivity analysis as for Fig. 10. Parameter number 22 refers to the mean day and standard deviation of diapause emergence, which was changed from $105 \pm 30$ to $75 \pm 15$ or $135 \pm 60$.

been established reliably (Randolph, 1994; Hay et al. 1996), such variable climatic data may be replaced by satellite data, perhaps leading to a more unified predictive relationship between tick population parameters and environmental conditions. The present rather ad hoc identification of significant climatic factors is nevertheless sufficient to predict tick seasonality even without the benefit of a full population analysis, again as at Ukunda.

The time-course of diapause termination also has a marked effect on the predicted seasonality in South Africa. Although diapause is thought to be controlled in some way by daylength (Rechav, 1981; Berkvens et al. 1995), the predictive relationship between daylength and either the onset of, or gradual emergence from, diapause has not yet been established for any one site, let alone taking account of any geographical variation in such a relationship. Empirical studies of this are urgently required.

A model of this form is potentially widely applicable to ticks other than $R$. appendiculatus in
Africa. Its simplicity makes it adaptable for other tropical tick species, and at the same time the inclusion of temperature-dependent variable development rates and diapause makes it appropriate for temperate species. There is nothing in the population dynamics of, for example, Ixodes ricinus in Europe that is not covered by this model. Population analysis for such a tick species, with annual or biannual seasonal peaks each composed of cohorts of ticks of mixed developmental history, is very difficult, but a model could generate simple predictions that could be tested against field data. The model could yield predictions of the future fate (development time and mortality) of ticks known to have fed at a certain time on hosts of a certain infection status, that will appear during future feeding seasons alongside ticks of a different infection history. At present there is no way of identifying the developmental, and therefore, the infection, origin of ticks observed in the field, but a model could assign a probability of past history to each tick. 

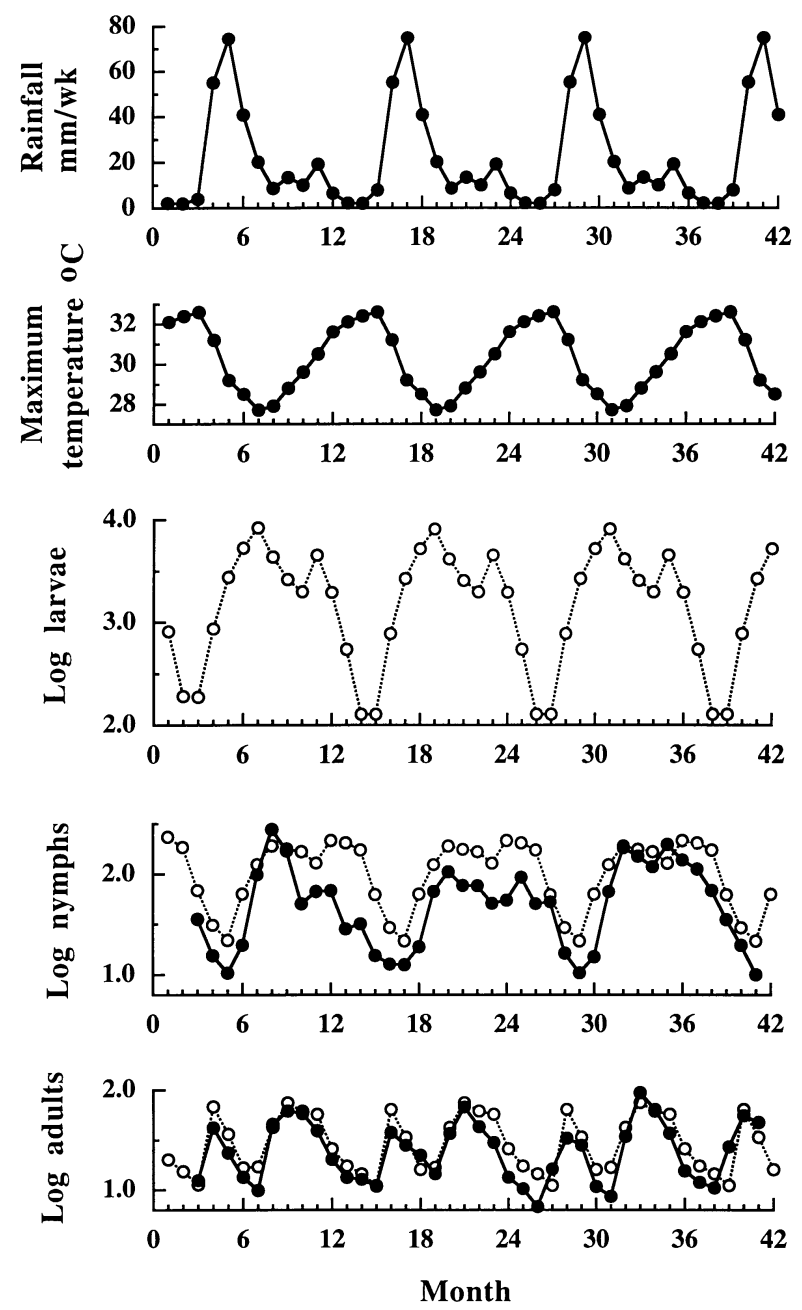

Fig. 12. Ukunda, Kenya. Seasonal variation in rainfall, maximum temperature and the mean number of Rhipicephalus appendiculatus larvae, nymphs and adults per host observed $(\bigcirc)$ and predicted by the model $(\bigcirc)$. For the observations, month 1 is January 1973 (from Newson, 1978). Rainfall is presented as the synoptic annual pattern (because rainfall was not recorded in all months of all years) and maximum temperature is taken from HMSO (1958) for Mombasa (36 km north of Ukunda). Observed nymphs $\times 10$.

The evidence from the present modelling exercise is that any spatial variation in the population dynamics of $R$. appendiculatus is determined principally by a single climatic factor that affects mortality, together with mean temperature that affects development rates. Biotic factors, such as host availability and host species composition, that may affect the tick's feeding probability and the intensity of density dependence as mediated by host-acquired resistance to ticks, respectively, will be superimposed on these principal climatic factors. The survival or extinction of local tick populations may therefore be predicted primarily by inserting into the model the appropriate climatic data for that locality. In this way the distributional limits of the tick may be defined biologically in terms of its population processes, rather than statistically by identifying areas whose environmental conditions match those known to be associated with tick presence (Rogers \& Randolph, 1993). Preliminary trials indicate that this approach is indeed workable.

Finally, we return to the raison d'être for vector population models, their use in predicting vector abundance and seasonality as risk factors for vectorborne diseases. Tick population models are only a means to the end of developing risk maps for tickborne diseases. The seasonal and annual variation in the number of ticks is only one, albeit essential, part of a full epidemiological model, that must also include the parameters of disease transmission dynamics, as have been described for East Coast Fever (Medley et al. 1993) and for Lyme borreliosis (Randolph \& Craine, 1995), that determine how many of those ticks are infective. Whether the pathogens are transmitted only by nymphs and adults, or by larvae as well, the dynamics of disease transmission are determined by the seasonal patterns of feeding by all three tick stages (nymphs cannot transmit unless larvae have already acquired infection from their bloodmeal). We need to be able to predict the numbers and interstadial development periods of each tick stage accurately. This model, RaPOP does exactly that, while also offering a useful tool to those veterinarians concerned with designing economical and effective intervention strategies to limit the direct damage caused to meat, milk and hide production by adult feeding ticks (inter alia Kaiser et al. 1988; Norval et al. 1988; Pegram et al. 1989; Mukhebi et al. 1989).

This paper is dedicated to the memory of Dr M. N. Kaiser, whose insistence on the value of counting larval ticks is, we hope, vindicated by these analyses. S.E.R. is supported by a Senior Research Fellowship in Basic Biomedical Science from the Wellcome Trust.

\section{REFERENCES}

AWERBUCH, T., SANDBERG, S. \& SPIELMAN, A. (1992). Critical abundance of hosts perpetuating the tick that transmits the agent of Lyme disease. American Fournal of Tropical Medicine and Hygiene (Suppl.) 45, 205. BERKVENS, D. L., PEGRAM, R. G. \& BRANDT, J. R. A. (1995). A study of the diapausing behaviour of Rhipicephalus appendiculatus and $R$. zambeziensis under quasinatural conditions in Zambia. Medical and Veterinary Entomology 9, 307-315.

BRANAGAN, L. D. (1973a). The development periods of the Ixodid tick Rhipicephalus appendiculatus Neum. under laboratory conditions. Bulletin of Entomological Research 63, 155-168.

BRANAGAN, L. D. (1973b). Observations on the development and survival of the ixodid tick Rhipicephalus appendiculatus Neumann, 1901 under quasi-natural conditions in Kenya. Tropical Animal Health and Production 5, 153-165. 
FLOYD, R. B., MAYWALD, G. F. \& SUTHERST, R. W. (1987). Ecological models. 2. A population model of Rhipicephalus appendiculatus. In Ticks and Tick-Borne Diseases. Proceedings of an International Workshop on the Ecology of Ticks and Epidemiology of Tick-Borne Diseases, Nyanga, Zimbabwe, February 1986. (ed. Sutherst, R. W.) pp. 72-75. ACIAR Proceedings No. 17, Canberra.

Haile, D. G. \& MOUNT, G. A. (1987). Computer simulation of population dynamics of the lone star tick, Amblyomma americanum (Acari: Ixodidae). Fournal of Medical Entomology 24, 356-369.

HAY, S. I., TUCKER, C. J., ROGERS, D. J. \& PACKER, M. J. (1996). Remotely sensed surrogates of meterological data for the study of distribution and abundance of arthropod vectors of disease. Annals of Tropical Medicine and Parasitology 90, 1-19.

H.M.s.o. (1959). Tables of Temperature, Relative Humidity, and Precipitation for the World. Part IV. Africa, the Atlantic Ocean south of $35^{\circ} \mathrm{N}$ and the Indian Ocean. H.M.S.O., London.

KAISER, M. N., SUTHERST, R. W. \& BOURNE, A. S. (1982). Relationship between ticks and zebu cattle in southern Uganda. Tropical Animal Health and Production 14, 63-74.

KAISER, M. N., SUTHERST, R. W. \& BOURNE, A. S. (1991). Tick (Acarina: Ixodidae) infestations on zebu cattle in northern Uganda. Bulletin of Entomological Research 81, 199-222.

KAISER, M. N., SUTHERST, R. W., BOURNE, A. S., GORISSEN, L. \& FLOYD, R. B. (1988). Population dynamics of ticks on Ankole cattle in five ecological zones in Burundi and strategies for their control. Preventive Veterinary Medicine 6, 199-222.

Kitron, U. \& MANnelli, A. (1994). Modeling the ecological dynamics of tick-borne zoonoses. In Ecological Dynamics of Tick-borne Zoonoses (ed. Sonenshine, D. E. \& Mather, T. N.) pp. 198-239. Oxford University Press, Oxford.

LORD, C. (1992). Nymphal Ixodes dammini: models of the temporal abundance patterns. International fournal for Parasitology 22, 759-765.

McCulloch, B., Kalaye, W. J., Tungaraza, R., SUda, B'Q. J. \& MBasha, E. M. S. (1968). A study of the life history of the tick Rhipicephalus appendiculatus - the main vector of East Coast Fever - with reference to its behaviour under field conditions and with regard to its control in Sukumaland, Tanzania. Bulletin of Epizootic Diseases of Africa 16, 477-500.

Medley, G., PERRY, B. D. \& YOUNG, A. S. (1993).

Preliminary analysis of the transmission dynamics of Theileria parva in eastern Africa. Parasitology 106, 251-264.

mount, G. A. \& Haile, D. G. (1987). Computer simulation of area-wide management strategies for the lone star tick, Amblyomma americanum (Acari: Ixodidae). Fournal of Medical Entomology 24, 523-531.

Mount, G. A., Haile, D. G., DAVEY, R. B. \& COOKSEY, L. M. (1991). Computer simulation of Boophilus cattle tick (Acari: Ixodidae) population dynamics. Fournal of Medical Entomology 28, 223-240.

MOUNT, G. A., HAILE, D. G., BARNARD, D. R. \& DANIELS, E. (1993). New version of LSTSIM for computer simulation of Amblyomma americanum (Acari: Ixodidae) population dynamics. Fournal of Medical Entomology 30, 843-857.

Mukhebi, A. W., Wathanga, J., PERry, B. D., IRVIN, A. D. \& MORZaria, S. P. (1989). Financial analysis of East Coast fever strategies on beef cattle production under farm conditions. Veterinary Record 125, 456-459.

NEWson, R. M. (1978). The life cycle of Rhipicephalus appendiculatus on the Kenyan coast. In Tick-borne Diseases and their Vectors (ed. Wilde, J. K. H.) pp. 46-50. CTVM, University of Edinburgh.

NORVAL, R. A. I., SUTHERST, R. W., KURKI, J., GIBSON, J. D. \& KERR, J. D. (1988). The effect of the brown ear tick Rhipicephalus appendiculatus on the growth of Sange and European breed cattle. Veterinary Parasitology 30, $149-164$.

NORVAL, R. A. I., PERRY, B. D. \& YOUNG, A. S. (1992). The Epidemiology of Theileriosis in Africa. Academic Press, London.

PEGRAM, R. \& BANDA, D. S. (1990). Ecology and phenology of cattle ticks in Zambia: development and survival of free-living stages. Experimental and Applied Acarology 8, 291-301.

PEgRAM, R. G., LEMCHe, J., CHIZUKA, H. G. B., SUTHERST, R. W., FLOYD, R. W., KERR, J. D. \& MCCOSKER, P. J. (1989). Effects of tick control on live weight gain in cattle in central Zambia. Medical and Veterinary Entomology 3, $313-320$

RANDOLPH, S. E. (1993). Climate, satellite imagery and the seasonal abundance of the tick Rhipicephalus appendiculatus in southern Africa: a new perspective. Medical and Veterinary Entomology 7, 243-258.

RANDOLPh, S. E. (1994). Population dynamics and density-dependent seasonal mortality indices of the tick Rhipicephalus appendiculatus in eastern and southern Africa. Medical and Veterinary Entomology 8, 351-368.

RANDOLPH, S. E. (1997). Abiotic and biotic determinants of the seasonal dynamics of the tick Rhipicephalus appendiculatus in South Africa. Medical and Veterinary Entomology 11, 25-37.

RANDOLPH, S. E. \& CRAINE, N. G. (1995). General framework for comparative quantitative studies on transmission of tick-borne diseases using Lyme borreliosis in Europe as an example. Fournal of Medical Entomology 32, 765-777.

RANDOLPH, S. E. \& STEELE, G. M. (1985). An experimental evaluation of conventional control measures against the sheep tick Ixodes ricinus (L) (Acari: Ixodidae). II. The dynamics of the tick-host interaction. Bulletin of Entomological Research 75, 501-518.

RECHAV, Y. (1981). Ecological factors affecting the seasonal activity of the brown ear tick Rhipicephalus appendiculatus. Proceedings of the International Conference on Tick Biology and Control, Grahamstown, pp. 187-191.

RECHAv, Y. (1982). Dynamics of tick populations (Acari: Ixodidae) in the Eastern Cape Province of South Africa. Fournal of Medical Entomology 19, 679-700.

Rogers, D. J. \& RANDOLPH, S. E. (1993). Distribution of tsetse and ticks in Africa: past, present and future. Parasitology Today 9, 266-271.

SANDberg, s., AWERbUCH, T. E. \& SPIElman, A. (1992). A comprehensive multiple matrix model representing 
the life cycle of the tick that transmits the agent of Lyme disease. Fournal of Theoretical Biology 157, 203-220.

SHORT, N. J., FLOYD, R. B., NORVAL, R. A. I. \& SUTHERST, R. W. (1989). Survival and behaviour of unfed stages of the ticks Rhipicephalus appendiculatus, Boophilus decoloratus and $B$. microplus under field conditions in Zimbabwe. Experimental and Applied Acarology 6, 215-236.
SHORT, N. J. \& NORVAL, R. A. I. (1981). The seasonal activity of Rhipicephalus appendiculatus Neumann 1901 (Acarina: Ixodidae) in the highveld of Zimbabwe Rhodesia. Fournal of Parasitology 67, 77-84.

VARLEY, G. C. \& GRADWell, G. R. (1968). Population models for the winter moth. In Insect Abundance (ed. Southwood, T. R. E.). Symposium of the Royal Entomological Society of London 4, 132-142. Blackwell Scientific Publications, Oxford. 